\title{
Torque Feedback for Steer-by-Wire Systems with Rotor Flux Oriented PMSM
}

\author{
K. Scicluna \\ C. Spiteri Staines \\ R. Raute
}

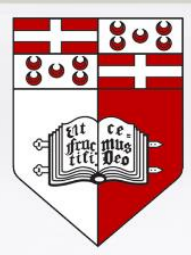




\section{Contents}

- System Overview

- Generation of Torque Feedback

- Steering Dynamics Monitoring

- Experimental Setup

- Experimental Results

- Conclusion 


\section{Steer-by-Wire Overview}

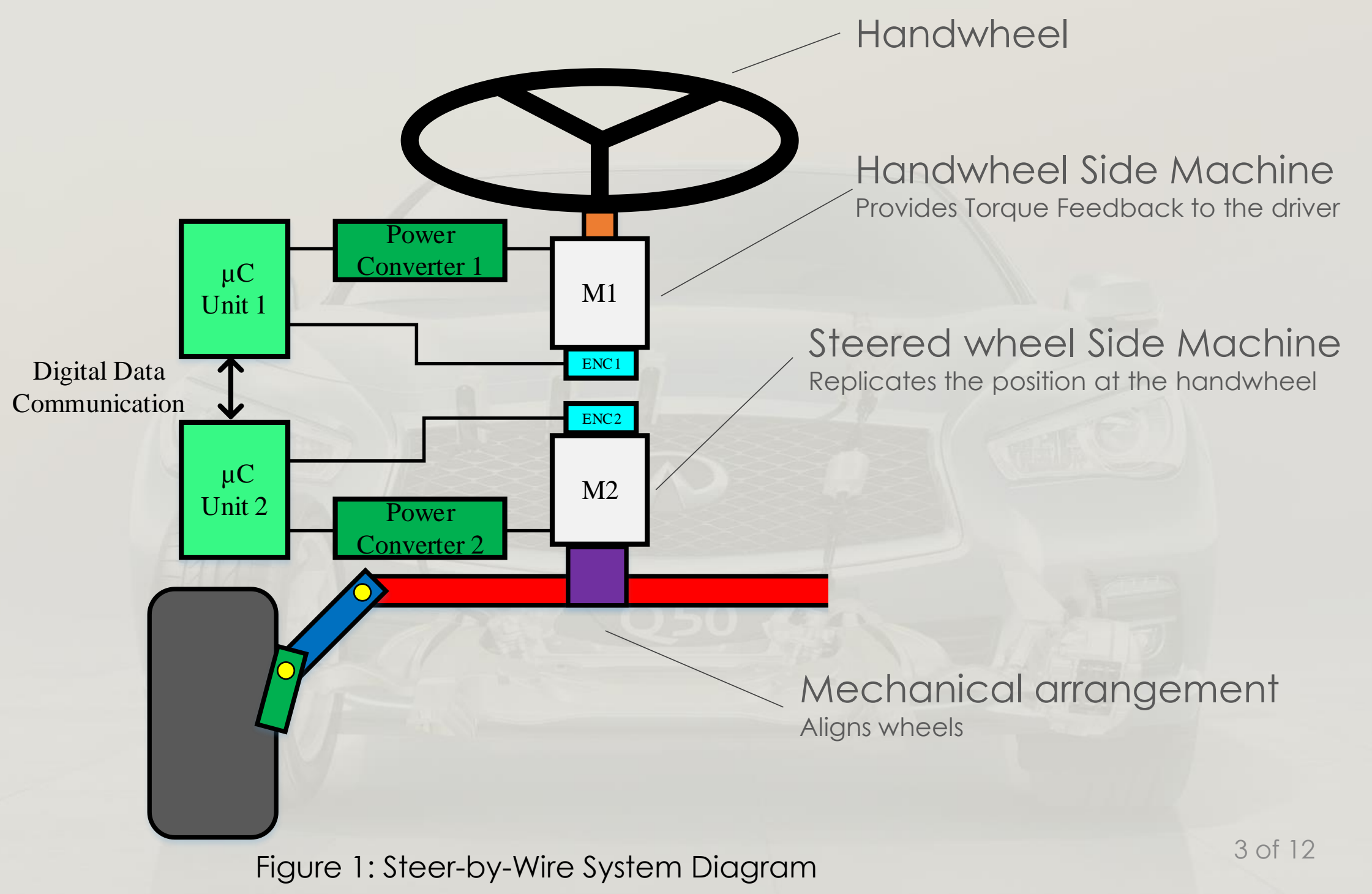




\section{Generation of Torque Feedback}

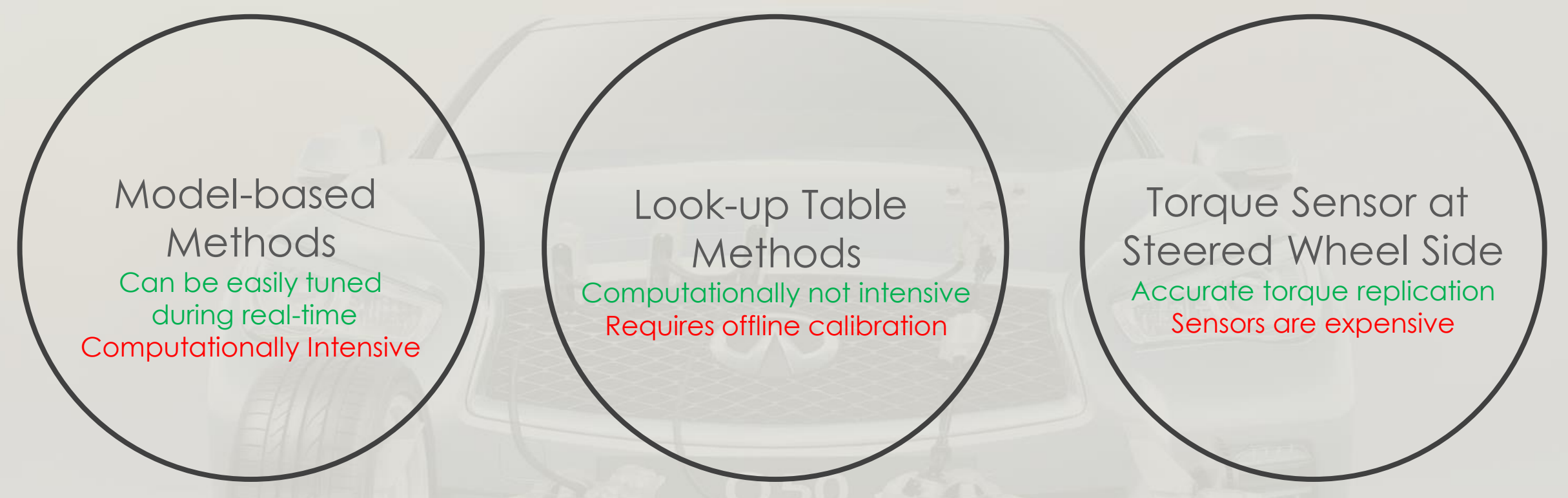




\section{Experimental Steering Dynamics Monitoring}

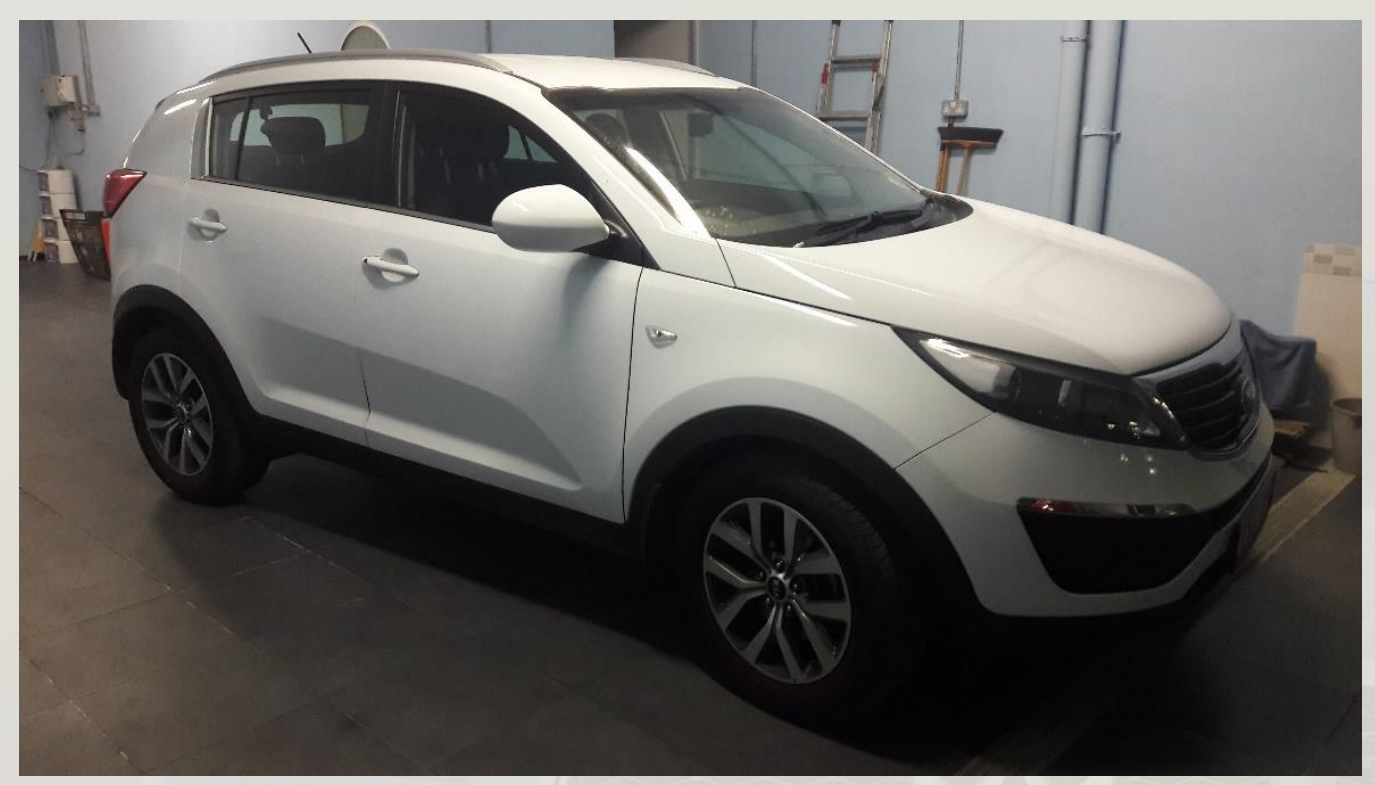

Figure 2 : Kia Sportage 2014 Test Vehicle
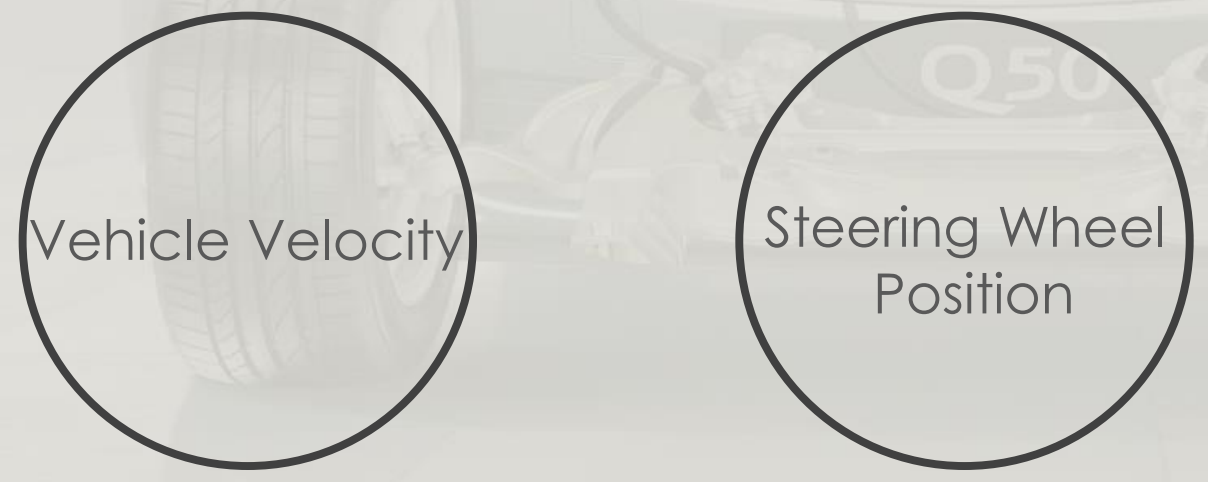

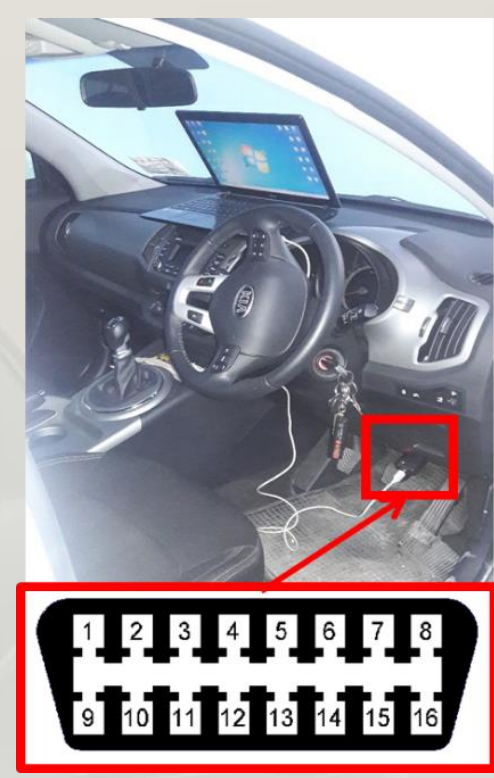

Figure 3: System Monitoring through On-Board Diagnostics (OBD)-II port

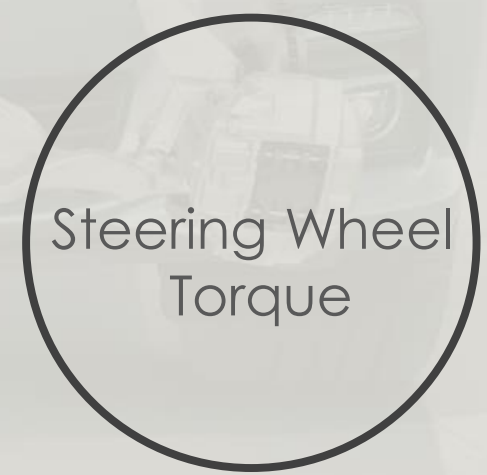




\section{Simplified Torque Generation}
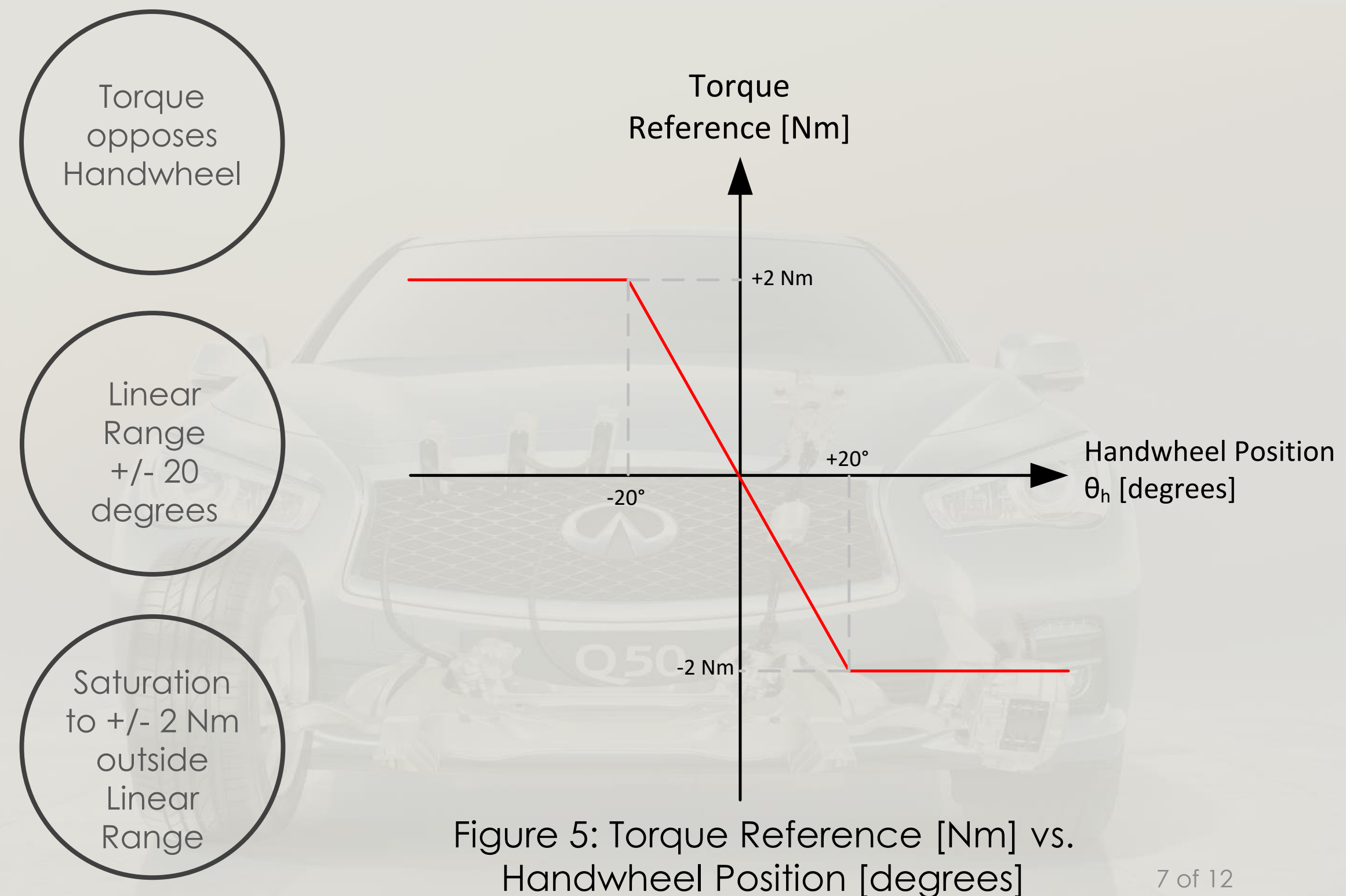

Figure 5: Torque Reference [Nm] vs. Handwheel Position [degrees] 


\section{Experimental Setup}

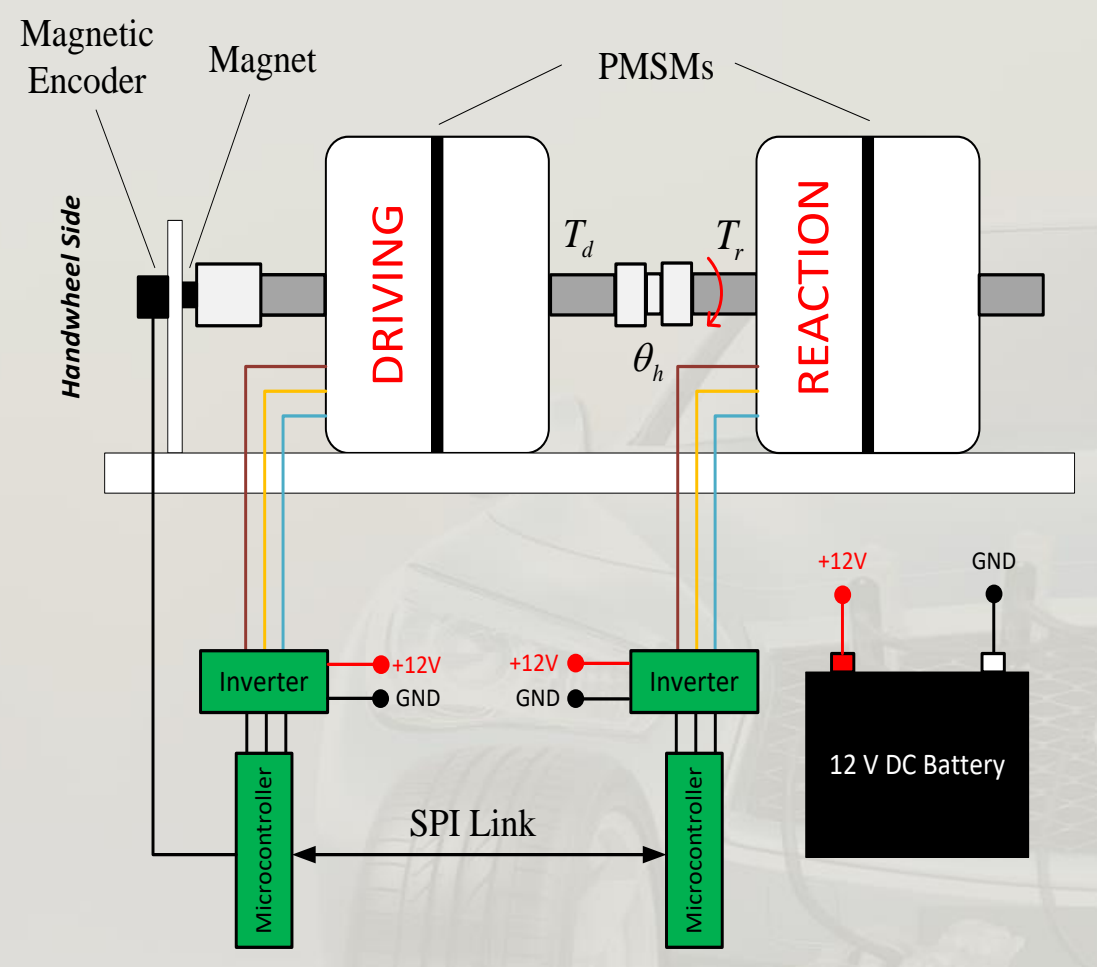

Figure 6: Steer-by-wire handwheel side setup illustration

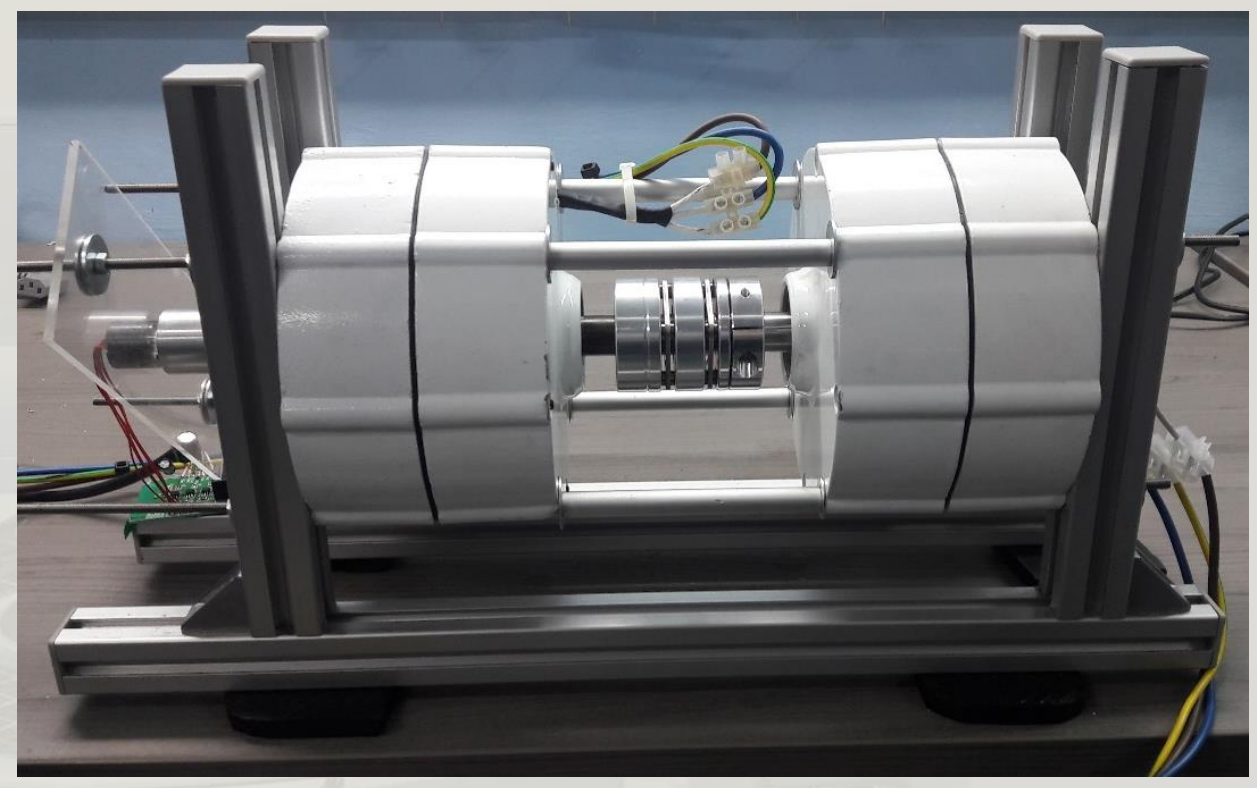

Figure 7: Steer-by-wire handwheel side PMSMs on experimental setup 


\section{Experimental Setup}
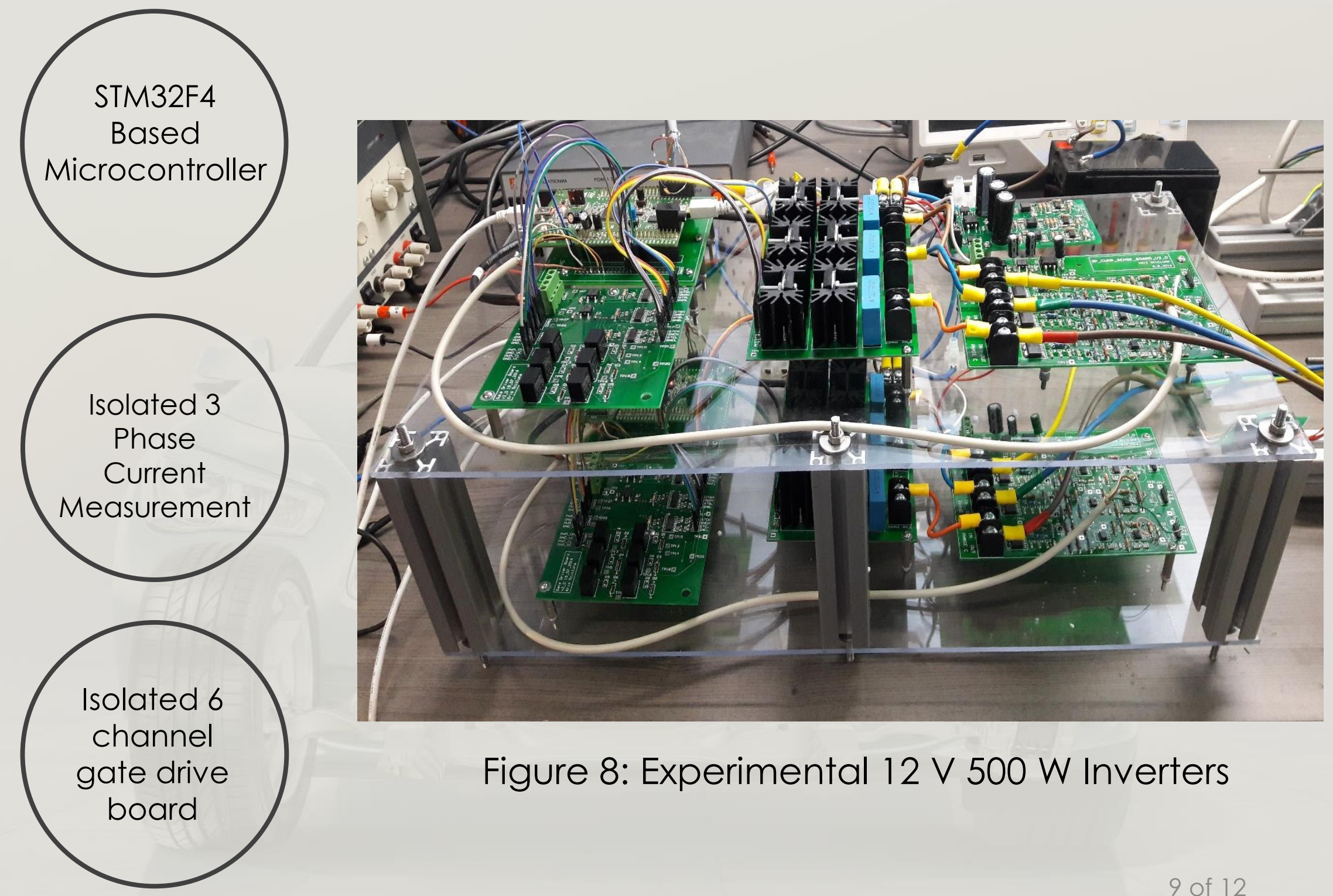

Figure 8: Experimental 12 V $500 \mathrm{~W}$ Inverters 


\section{Experimental Setup}

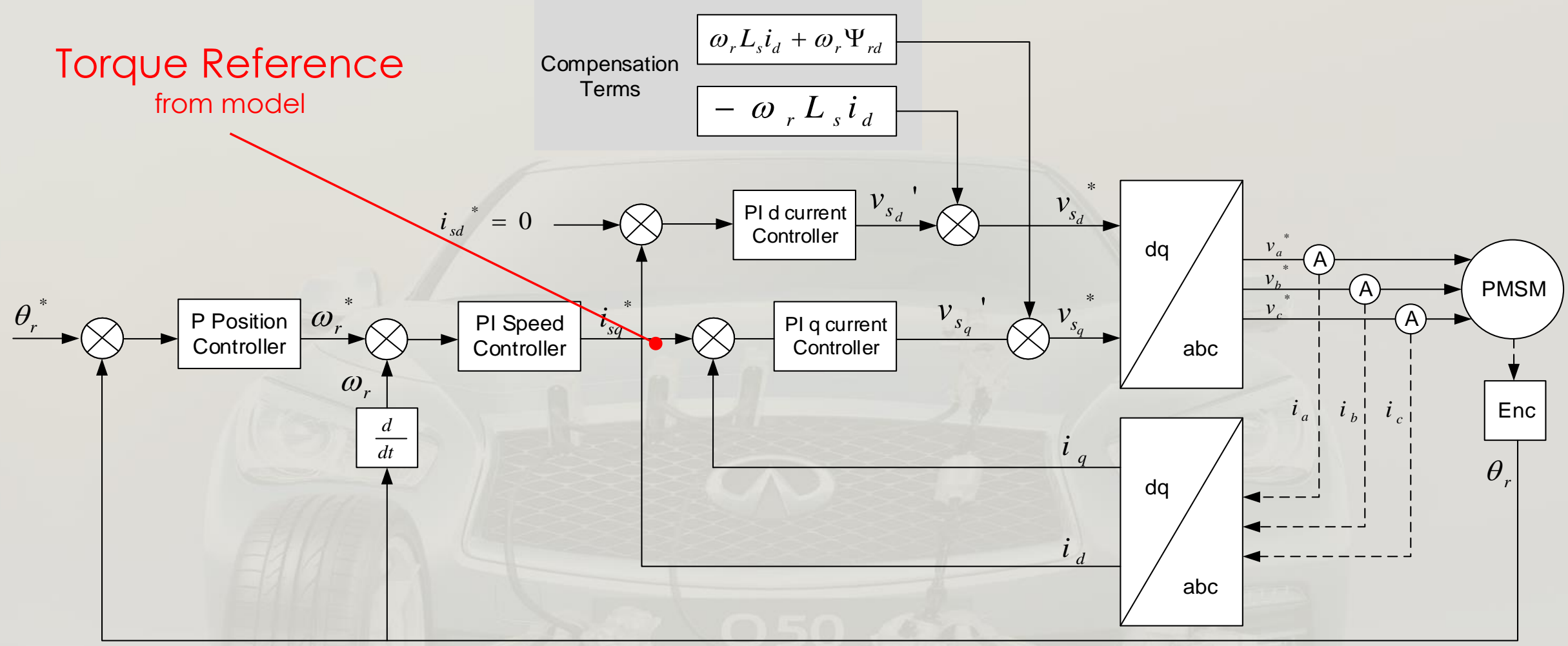

Figure 9: Rotor Flux Oriented Control Topology 


\section{Experimental Results}

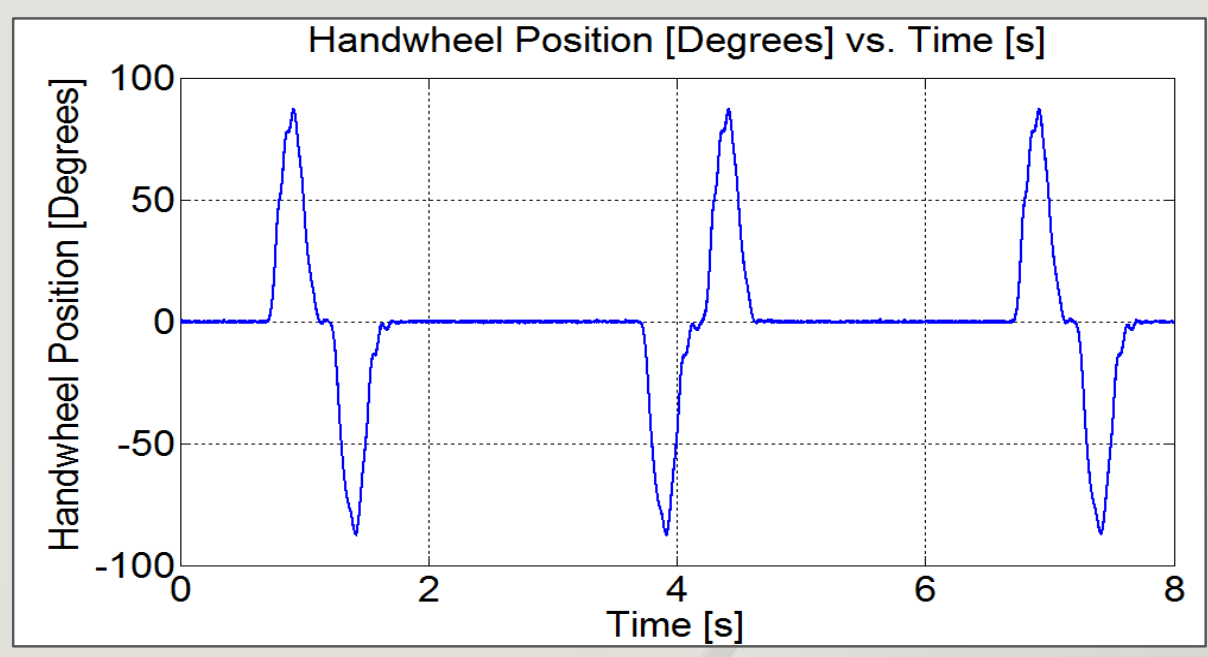

Figure 10: Handwheel Shaft Position set by position controlled driving machine.

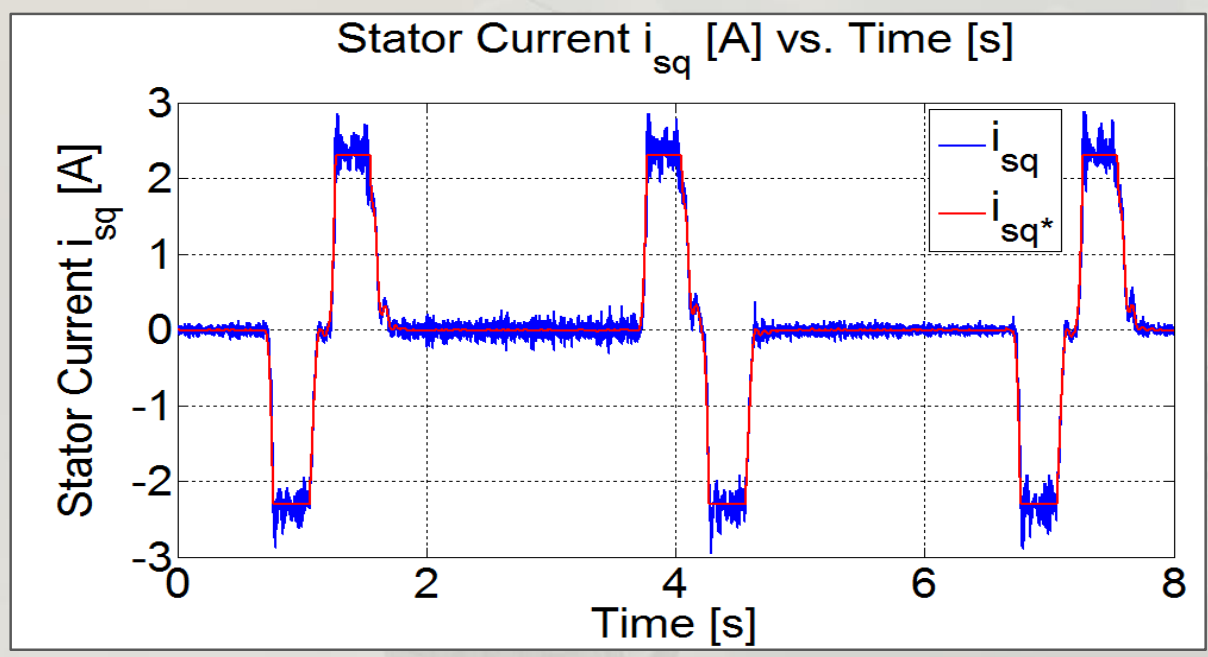

Figure 12: Synchronous frame Stator q axis currents of the Reaction current controlled machine.

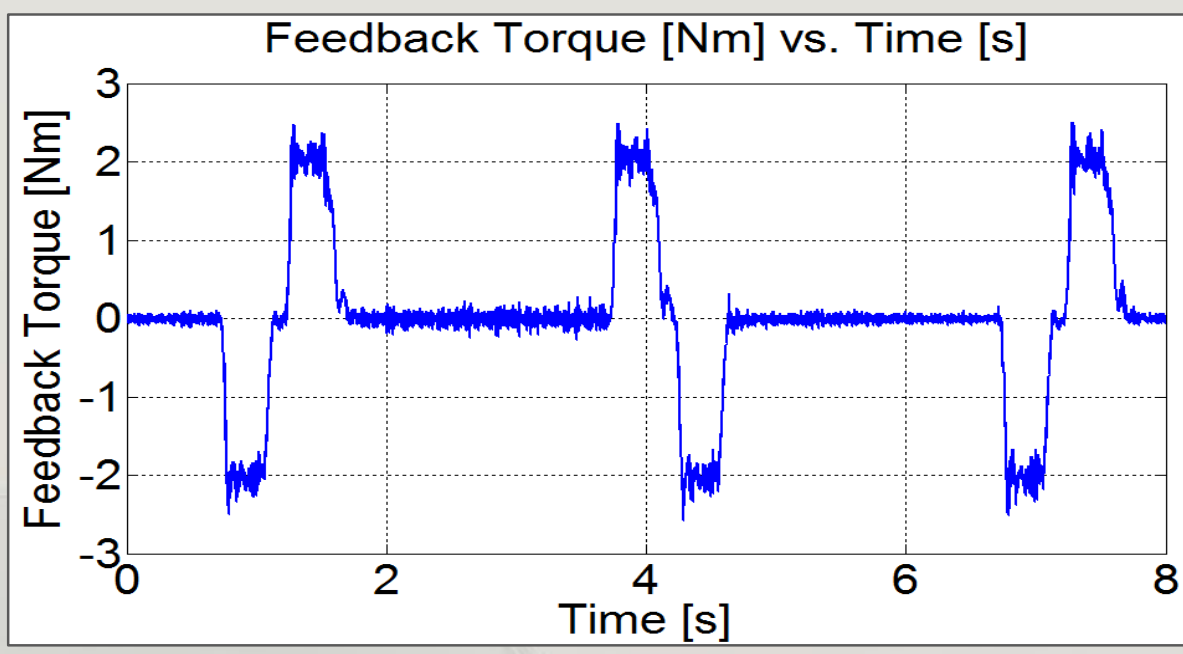

Figure 11: Feedback Torque generated by the reaction current controlled machine.

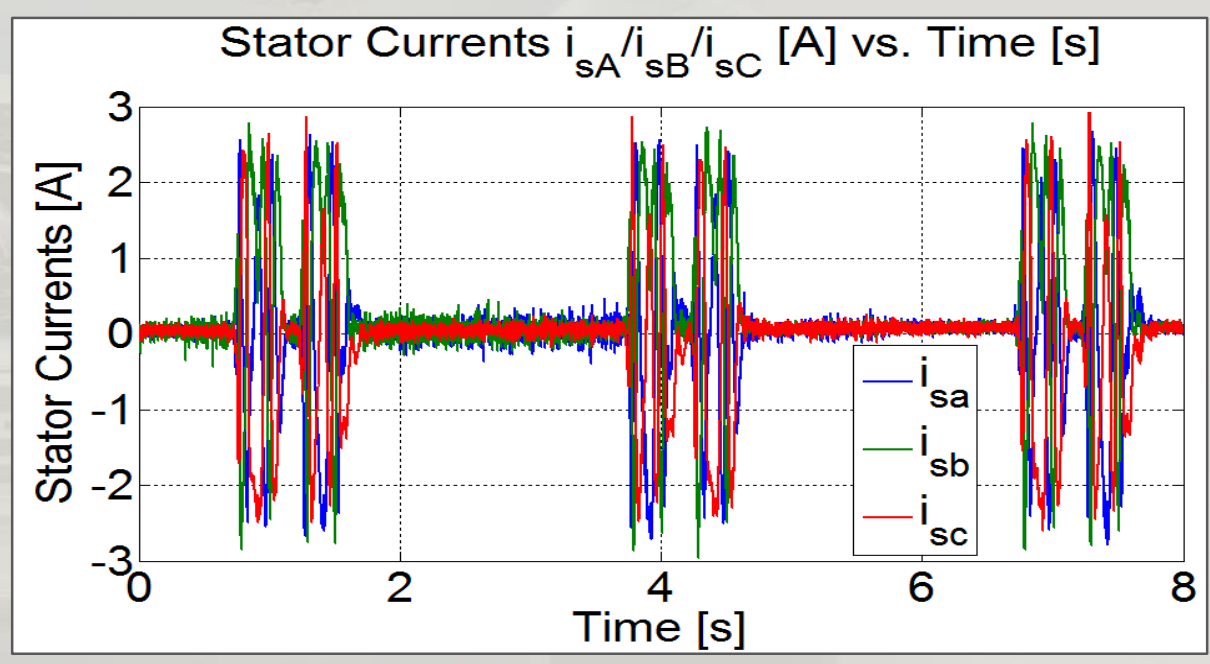

Figure 13: Three phase stator currents of the reaction current controlled machine. 


\section{Conclusions}
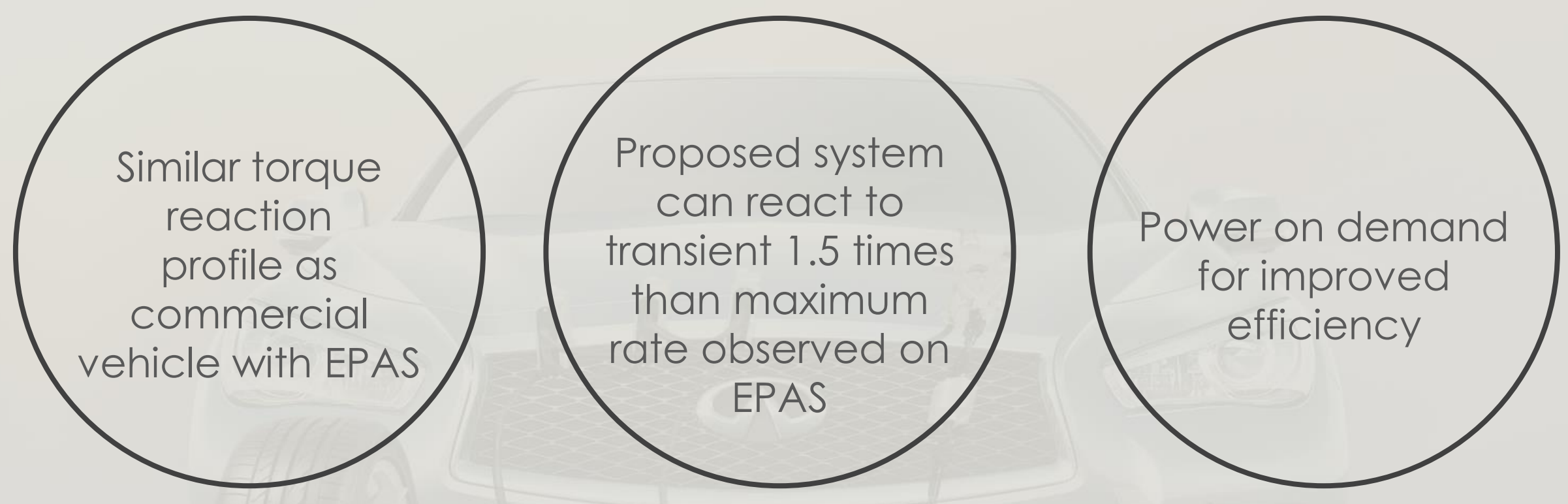


\section{Discussion}

\section{Authors}

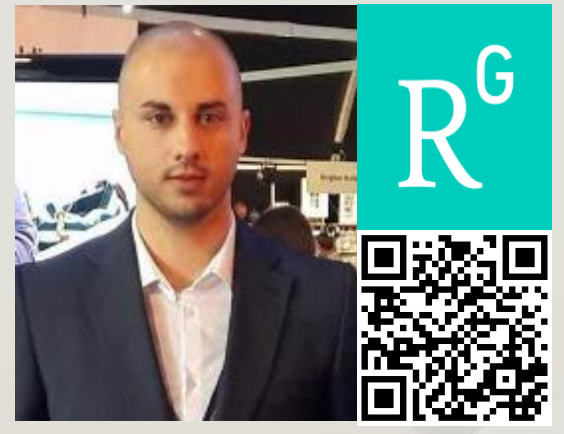

Kris Scicluna

PhD Research Student, Department of Industrial Electrical Power Conversion, University of Malta.

Lecturer, Institute of Engineering and Transport, Malta College for Arts, Science and Technology

Email: Kris.Scicluna@mcast.edu.mt

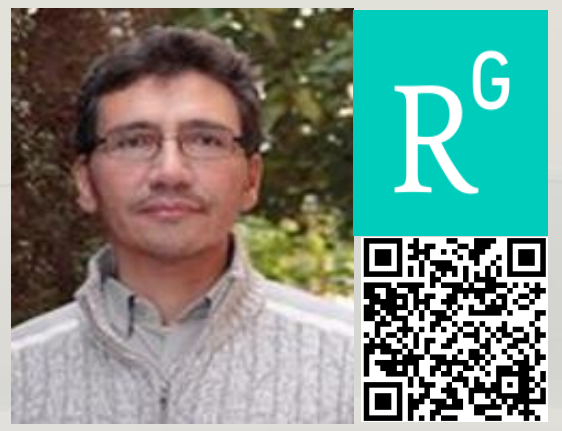

\section{Cyril Spiteri Staines}

Professor,

Department of Industrial Electrical Power Conversion University of Malta.

Email: cyril.spiteri-staines@um.edu.mt

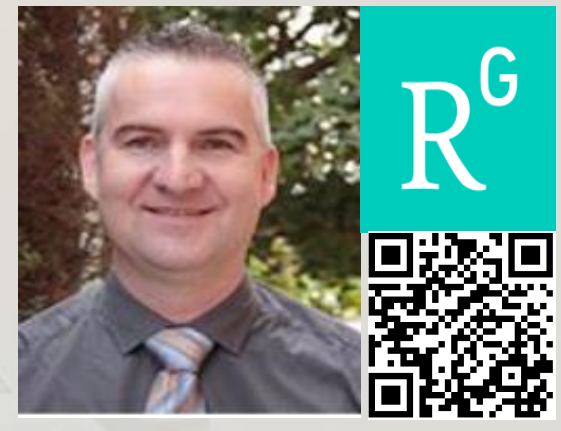

\section{Reiko Raute}

Lecturer,

Department of Industrial Electrical Power Conversion, University of Malta.

Email: reiko.raute@um.edu.mt

About the Department of Industrial Electrical Power Conversion - The Department of Industrial Electrical Power Conversion, IEPC, forms part of the Faculty of Engineering at the University of Malta. IEPC has been at the forefront of research and lecturing in the following areas of electrical engineering: Power Electronics and Distributed Generation; Power Systems and Grid Integration of Renewable Energy Sources (RES); Electrical Machines and Drives; and Electrical Services. Website: https://www.um.edu.mt/eng/epc

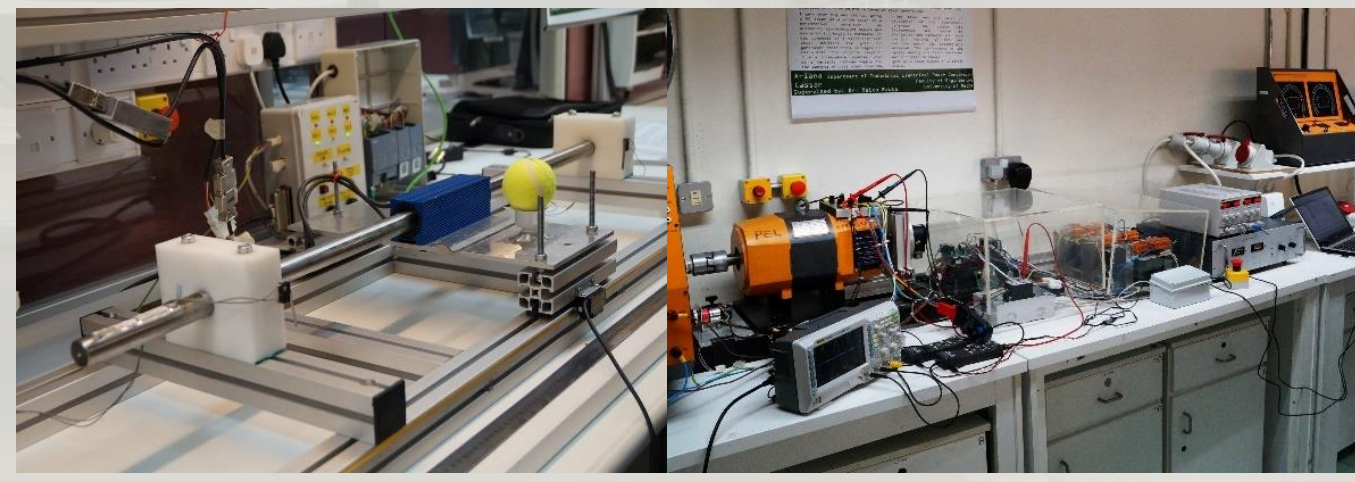

